\title{
Zur Casuistik des atypischen Herpes zoster.
}

\author{
Von \\ Dr. H. Staub \\ in Seen-Zirich,
}

\begin{abstract}
Das Krankheitsbild des Herpes zoster ist den Aerzten. seit langer Zeit bekannt; die Lehre von seiner Genese dagegen ist ein Product der neueren Medicin. Zwar sind schon zu Beginn unseres Jahrhunderts verschiedenen Autoren Beziehumgeu der Hautaffection zum Nerrensysteme aufgefallen, ja man suchte sogar - zum Theil mit positivem Erfolge - nach anatomischen Veränderungen an den peripheren Nerven. Indess ist es doch erst v. Bärensprung gelungen, den Zusammenbang der Erscheinungen auf der Haut mit einer Erkrankung. der Nerven klar zu legen, gestützt auf eingehende Untersuchungen an der Leiche. Wenn nun auch in jüngster Zeit einige Punkte auf Widerspruch gestossen sind, so ist doch das Wesentliche der v. Bärensprung'schen Resultate in der Folgezeit durch eine grössere $\mathrm{Zahl}$ einschlägiger Forschungen. immer und immer wieder bestätigt worden.

Während damit den weiteren Untersuchungen über die Aetiologie der Krankheit der richtige Weg gewiesen wurde, so ist inzwischen durch klinische Beobachtungen auch die Symptomatologie des Zosters wesentlich bereichert worden. Es ist rorab ein Verdienst $K$ a p osi's, gewisse atypische Formen der Gürtelkrankheit als solche erkannt und veröffentlicht zu


baben. Einige weitere Krankengeschichten verdauken wir dann Ne u man, Leloir, Kopp, Doutrelepont, welche selber indessen ihre Fälle nicht mit Bestimmtheit als Zosteren aufgefasst haben.

$\mathrm{Zu}$ Beginn der 80er Jahre ist nun im Cantonsspitale zu Glarus ein analoger Fall während langer Zeit beobachtet worden. Dessen Krankengeschichte ist folgende:

Trümpi Albertine, 16 Jahre, Fabrikarbeiterin, von Ennenda (Glarus), stammt von einem gesunden Vater und einer an Lungenschwindsucht verstorbenen Mutter; eben dieser Krankheit sind anch zwei Geschwister erlegen. Pat. selber war bis zu ihrem jetzigen Leiden nie wesentlich krank. Vor 4 Jahren entstanden ohne nachweisbare Ursache auf der rechten Seite des Abdomens im Bereiche der Axillarlinien kleine Geschwüre, die sich entweder rasch wieder schlossen, oder erst grösser wurden und dann ebenfalls spontan langsam ausheilten mit Hinterlassung deutlicher Narben. Während also die Geschwüre hier sich schlossen, brachen dort neue auf, und so breitete sich der Process allmälig aus nach hinten auf die Lumbalgegend, namentlich aber nach vorn gegen die linea alba zu. Stille gestanden ist die Krankheit niemals. Vor 2 Jahren zeigte sich die Affection während 4 Wochen auf cier Vorderfläche des rerhten Oberschenkels. Anfangs klagte Pat. wenig; seit einem Jahre aber treten zaweilen intensive Schmerzen auf, die in der Lendengegend beginnen und gegen den Nabel hin ausstrahlen. - In den letzten Wochen wurde Pat. oft von starkem Schwindel und Kopfweh befallen. - Die Menstruation war regelmässig. Bemerkenswerth ist die Angabe der Pat., dass, wenn grössere Geschwüre bestanden, diese oft zur Zeit der Periode bluteten.

Bei der Aufnahme in die Anstalt am 21. Oct. 1882 zeigte sich Folgendes:

Es handelt sich um ein anämisches, dürftig genährtes Mädchen von sehr beschränkter Intelligenz. Die inneren Organe sind intact, die Temperatur normal; keine Drüsenschwellungen; im Urin weder Zucker noch Eiweiss. Auf der rechten Seite des Abdomens zeigt sich eine Narbenfläche, die in der hinteren Axillarlinie beginnt und, sich leicht fächerformig ausbreitend, bis zur verlängerten Parasternallinie reicht. Die einztlnen Narben stellen prominirende weiche Leisten dar, die parallel zu einander in horizontaler Richtung verlaufen, oder seltener eine strahlige Anordnung zeigen. Die nach unten und hinten gelegenen Züge sind blass, diejenigen in der Nähe des Rippenbogens und des Nabels sind yeröthet und stärker prominent; einer der letzteren zeigt etwa 3 Finger breit rechts vom Nabel eine oberflächliche Usur. Die zwischengelegene Hant ist intensiv pigmentirt, so dass das Ganze ein exquisit streifiges 1) der marmorirtes Aussehen bietet. Die Lumbalgegend ist frei von Narben, zeigt nur einige unregelmässige Pigmentringe. Eben solche, aber kleinere 
findet man in grösserer Anzahl auf der Vorderfiäche des rechten Oberschenkels, unmittelbar unterhalb der Inguinalfalte; auch bemerkt man hier einige weisse, vortretende Narbenzüge. - Die Semsibilität ist im Gebiete der Narbe und in deren nächster Umgebung sehr herabgesetzt für Berührung, Nadelstiche, Druck, Wärme und faradischen Strom. An den übrigen Stellen des Körpers bestehen zur Zeit keine Sensibilitätsstörungen. - Pat. klagt über Druckempfindlichkeit über der Symphyse; im übrigen hat sie gegenwärtig keine Beschwerden.

10. Nov. 1882. Da die erwähnte Narbenusur unter Borsalbe sich nicht schliessen wollte, wurde sie vor einigen Tagen mit Jodoformcollodium bepinselt, worauf sie aber grösser und schmerzhaft, die Umgebung stärker geröthet wurde. Die Abendtemperaturen sind seither meist etwas erhöht, bis 37,8 im max.

22. Nov. Das Gerchwür hat sjch bis hente bedeutend vergrössert nach der Fläche sowohl, als in die Tiefe; es zeigt ein sehr schlechtes Aussehen: der Grund ist stark injicirt, spontan and bei Berührung schmerzhaft, sehr leicht blutend; er trägt einige isolirte, z. T. necrotische Hautfetzen, die sich noch nicht abgestossen haben. - Therapie: local Camphersalbe; innerlich Bromkali. - Die Abendtemperaturen immer erhöht, doch nie bis $38^{\circ}$.

27. N o v. Die heutige (wegen der grossen Empfindichkeit in Chloroformnarcose vorgenommene) Untersuchung zeigt ein nun halb handtellergrosses, $2 \mathrm{Cm}$. tiefes Geschwür, das ca. 3 Finger breit rechts vom Nabel gelegen ist. Der Grund zeigt einen grauweissen Belag; blutet sehr leicht; der Geschwürsrand wird durch zackige, z. T. necrotische und unterminirte Haut gebildet. Ausserdem bemerkt man mehrere kleinere Ulcerationen, die als horizontale Furchen verlaufen und sämmtlich in das grosse, erst erwähnte Geschwür einmünden. Die Ulceration hat sich namentlich in den letzten Tagen rasch vergrössert, indem sie einen exquisit malignen, destruirenden Charakter annahm. - Die Abendtemperatur erreicht heute Abend zum ersten Male $38^{\circ}$. - Therapie: permanentes Bad.

2. Dec. Am 27. Nov. traten die $\mathrm{Menses}$ ein, worauf die Temperatur rasch auf $38,6^{\circ} \mathrm{stjeg}$, sich einige Tage auf dieser Höhe hielt, um heute, mit Schluss der Periode, auf 37,7 herabzufallen. Das Aussehen der Wunde hat sich inzwischen nicht verändert.

14. Dec. Seit 8 Tagen vergrössert sich das Geschwür wieder langsam, während gleichzeitig die Temperatureurve stetig steigt und bereits 38,3 erreicht. Pat. klagt seither über Schmerzen in der Wunde.

9. Jänner 1883. 1. Operation. Auch bis heute hat sich der Process unaufhaltsam weiter entwickelt; das Geschwür ist grösser und tiefer geworden; aus dem Grunde, der mit necrotischen Gewebsfetzen bedeck ist, traten mehrmals erhebliche Blutungen auf. Der Ausbreitung der Krankheit entsprechend ist die Temperatur bis nahe an $39^{\circ}$ gestiegen, während die Schmerzen immer unerträglicher wurden und sich weder durch Morphium noch Chloralhydrat beschwichtigen liessen. 2stündlich gewechselte, nasse Salicylcompressen vermochten den aashaften Geruch 
nicht zu beseitigen. Da Pat. inzwischen sehr heruntergekommen ist, erscheint ein operativer Eingriff dringend indicirt, und das um so mehr, als man sich trotz der Anamnese des Eindrucks nicht erwehren kann, es möchte sich um eine maligne Neubildung handeln. In Chloroformnarcose wird heute das Geschwür entfernt. Seine sehr hart infiltrirte Umgebung weist den Weg, indem man, um sicher im Gesunden zu operiren, immer ca. $1 \mathrm{Cm}$. ausserhalb der harten Partien operirt. Mit Messer und Scheere dringt man vor, durch Fascien, Bauchmusculatur etc, bis man schliesslich aufs Peritone um gelangt. Auch dieses ist bereits indurirt, so dass ein 5-Frankstückgrosses Stück desselben mit entfernt werden muss. Mit der entfernten Partie des Bauchfelles ist ein Strang des grossen Netzes der bo verwachsen; er wird abgebunden und durchtrennt. - Die Peritonealwunde wird lineär mit Catgut vereinigt; den mächtigen Wundtrichter der Bauchwand schliessen versenkte, oberflächliche und Entspannungsnäbte; die letzteren sind so angelegt, dass die Wundlinie die Form eines Kreuzes bekommt. Die Kreuzungsstelle bleibt etwas offen und sichert den Abfluss des Wundsecretes. Listerverband. - Die Bluturg war mässig. Trotzdem ist Pat. sebr collabirt. - Abends hat sich Pat. etwas erholt, doch ist der Puls noch klein und frequent. T. 36,3.

Das Präparat wurde an Herrn Prof. Klebs in Zürich geschickt. Er vermuthete ursprünglich, es möchte sich um einen gangränösen Infectionsprocess handeln, ähnlich dem Hospitalbrande, aber langsam fortschreitend und local bleibend. Indessen war er nicht im Stande, Microorganismen im Gewebe nachzuweisen. Dagegen fand er, namentlich in den musculären Theilen des Präparates, "entschieden sarcomatöse Bildungen, kolossale Gefässentwicklungen in einem wuchernden Gewebe fötalen Charakters, eckige und spindelförmige Zellen mit geringer Zwischensubstanz; dazwischen Reste atrophischer Muskelfasern“. Da das Muskelgewebe nun gerne der Sitz solcher Neubildungen ist und anderseits Sarcome in der Form flacher fressender Geschwire vorkommen, so erschien Herrn Prof. Klebs eine solche Annahme zutreffend, falls sie mit dem klinischen Verlaufe übereinstimmen sollte.

11. Jänner 1883. Bis jetzt afebriler Verlauf. Puls gut. Keine Schmerzen.

15. Jänner. Gestern vorübergehend Temperatursteigerung $\left(38^{\circ}\right)$. Sonst kein Fieber. Befinden gut.

29. Jänner Gestern wieder $38^{\circ}$; sonst normale Temperaturen. Befinden gut. Wundränder an 2 kleinen Stellen necrotisch. Wunde sonst. geschlossen.

19. Februar. Vom 14.-18. plötzliche Temperatursteigerung bis. $39,6^{\circ}$. Am Abdomen ist nichts besonderes zu sehen. $\left.{ }^{1}\right)$

b) In der Krankengeschichte fehlen während längerer Zeit die Angaben über den Eintritt der Periode; zählt man aber, in Berücksichtigung ihres sonst regelmässigen Eintreffens, vom zuletzt notirten Male ab je 4 Wochen ab, so musste auf diese Zeit eine Menstruation fallen. 
1. März. Vom 27.-29. Februar abermals Temperatursteigerung bis 38, $9^{\circ}$. Während dieser Zeit bildete sich spontan auf der frischen Narbe eine kleine, oberfïchliche Ulceration. Sonst alles geschlossen und von gutem Aussehen.

19. März. Das erwähnte Geschwür hat sich erst etwas vertieft; in den letzten Tagen ist es wieder kleiner geworden. Die von der Operation datirende Narbe ist stark gewuchert und stellt nun ein dickes Keloid dar. - Befinden gut.

13. April. Nachdem sich das Geschwür geschlossen hatte, ist soeben unter stechenden Schmerzen ein neues entstanden auf dem äusseren Schenkel der kreazförmigen Operationsnarbe. Ein vesiculäres Vorstadium wurde nicht constatirt; das erste, was man bemerkte, war ein einfacher Epitheldefect, so wie er jetzt besteht; es sieht aus, als ob durch $A n$. streifen das Epithel der Narbe weggescheuert worden wäre; das Corium liegt nackt zu Tage; die Umgebung zeigt leichts Injection, sonst keine weiteren Erscheinungen.

25. Mai. Nachdem bisher alles sehr gut gegangen, das erwähnte Geschwür auf der Narbe zwar äusserst langsam, aber stetig sich schloss, so dass es heute nur mehr ganz klein ist, so traten nun neuerdings unter. Fieber wieder starke stechende Schmerzen auf der rechten Seite des Abdomens auf. Heute Morgen bemerkt man nun ein ausgebreitetes vesiculöses Exanthem in der erkrankten Gegend. Man kann deutlich verschiedene Stadien erkennen, denn neben kleinen rothen Fleckchen findet man Bläschen, die einen hellen, gelblichen Inhalt durchschimmern lassen, und von einem röthlichen Hofe umgeben sind; andere Bläschen sind dunkel blauroth, ihre Spitze mehr weniger eingetrocknet und eingezogen; ein rother Hof umsäumt dieselben. Endlich findet man an gewissen Stellen bereits Schorfe von $1 / 4-3 / 4 \mathrm{Cm}$, Durchmesser. Dieselben sigd von dunkler Färbung, ganz wenig unter das Niveau der Umgeb ung eingesunken; ein rother Hof besteht hier nicht. Die Efflorescenzen stehen theils in kleinen Gruppen, theils sind sie unregelmässig disseminirt. Am zahlreichsten findet man sie im alten Narbenrevier, d. h. zwischen vorderer Axillar- und Parasternallinie einerseits, Inguinalfalte und Rippenbogen anderseits; unter anderen fällts eine schön ausgebildete Gruppe über der Spina ant. sup. ossis ilei auf. Ausserdem finden wir am Oberschenkel 3 Querfinger unter- und ausserhalb der Labiocruralfalte eine Gruppe von 2 rothen Flecken und zwei Schörfchen; ferner über der 7. Rippe in der mittleren Axillarlinie zwei ältere Bläschen; über der Spina post. sup. einen Schorf von $3 / 4 \mathrm{Cm}$. Durchmesser und schliesslich in der Glutäalgegend zerstreut einige rothe Flecken. Die linke Körperhälfte ist vollkommen fiei.

26. Mai. Keine frischen Bläschen; die alten trocknen mehr und mehr ein, während sie gleichzeitig dunkelblau werden und thre Umgebung eine intensivere Röthung und leichte Anschwellung zeigt; eine Anzahl hat sich auch bereits zu Schorfen, ähnlich den gestern erwähnten, verwa ndelt. 
27. Mai. Sämmtliche Bläschen verschorft.

28. Mai. Die grössern Schorfe sind von einem Ringe normal aussebender Haut umgeben, während sich an dessen Peripherie Pigment ansammelt.

30. Mai. Ein grösserer Schorf am rechten Oberschenkel, sowie zwei kleinere über der Spina ant. sup. haben sich unter mässiger Eit erung abgestossen und ein oberflächliches Geschwür zurückgelassen.

1. Juni. In der Inguinalgegend hat sich noch ein weiteres Geschwürchen gebildet. Alle andern Efflorescenzen sind unter dem Schorfe geheilt; auch die früher erwähnte Narbenulceration ist nun geschlossen; es datiren mithin sämmtliche zur Zeit bestehenden Geschwüre von der am 25. Mai erfolgten Eruption her.

4. Ju in . Die continuirlichen Schmerzen in der rechten Bauchseite exacerbirten gestern; heute sieht man rechts rom Nabel drei stecknadelkopfgrosse, braunrothe Flecken, die auf Druck nicht ganz erblassen. Die: Abendtemperaturen halten sich irnmer um $38^{\circ}$.

8. Juni. Das eine (vordere) Geschwür über der Spina ant. sup. hat sich um das zweifache ausgedehnt und ist beträchtlich tiefer geworden: Der Grund zeigt einen grauweissen Belag; die Ränder sind stark geröthet und gewulstet.

13. Juni. Das Geschwür am rechten Oberschenkel und in der In: guinalgegend geschlossen; intensive Pigmentation der Umgebung; dasjenige über der Spina ant. sup. ist eher etwas kleiner geworden; auch hier bräunt sich die Umgebung.

25. Jun i. Das vordere Geschwür über der Spina verkleinert sich stetig, zeigt aber noch die gleiche Beschaffenheit wie am. 8. Juni; das. hintere dagegen hat sich ganz geschlossen. Auch hier ist eine sehr starke Pigmentirung in der Umgebung aufgetreten. - Abendtemperaturen immev über $38^{\circ}$.

29. Juni. Eintritt der Periode.

2. Juli. Das Geschwär vergrössert sich bei steigender Temperatur ; seine Ränder sind stark geschwollen; aus der Tiefe erfolgte heute Früh eine Blutung.

4. Juli. Die Abendtemperaturen reichen nahe an $39^{\circ}$. Bei der rasch fortschreitenden Gangrän des Geschwürsgrundes sind die Hautränder unterminirt, zerfetzt, zum Theil necrotisch.

8. Juli. Das Fieber stieg gestern und heute Abend bis $40^{\circ}$. Das Geschwür stellt bereits einen eigrossen Substanzverlust dar; in der Tiefe gangränöses, stinkendes Gewebe. Die ganze Umgebung ist ödematös geschwollen.

9. Juli. 2. Operation. Das Geschwür wird hente excidirt, indem man ausserhalb der harten Infiltration in die Tiefe geht. Nach oben gelingt es, die derbe Masse vom hier unversehrten Musculus transversus abzupräpariren; unten dagegen ist dieser Muskel von einem harten Knoten durchsetzt; bei der Entfernung desselben ist man genöthigt; so weit in die Tiefe zu gehen, dass das Peritoneum an einer kleinen Stelle eröffnet 
wird. Die Serosa selhst ist aber diesmal noch intact. - Die kleine Bauchfellwunde wird mit 2 Catgutsuturen geschlossen. Dann wird mit Magist. Bismuth.-Emulsion ausgespült und die Wunde durch fortlaufende Seidennaht geschlossen. Zum Zwecke der Drainage wird der obere Wundwinkel offen gelassen; es werden hier zwar einige Nähte angelegt, dieselben aber nicht geknotet. -- Ein Schnitt durch die exstirpirte Masse zeigt, dass das entfernte Muskelstück infiltrirt und ödematös ist und im Centrum einen kleinen Abscess beherbergt.

Abends noch starke Chloroformnachwirkung. T. 36,90.

10. Juli. Auch heute noch Uebelkeit und Brechen.

15. Juli. Verbandwechsel. In der Mitte der Nahtlinie eine helle Blase als Zeichen der grossen Spannung; sonst gutes Aussehen. Die paar offen gelassenen Nähte werden nun ebenfalls geknotet. - Befinden der Pat. bis zur Stunde gut; kein Fieber.

18. J ali. Verbandwechsel. In. Folge der grossen Spannung haben viele Nähte durchgeschnitten, so dass sich heute eine kleiu handtellergrosse Wundfläche präsentirte. Temperaturen immer normal.

21. Juli. Verbandwechsel. Auch die letzten Nähte haben durchgeschnitten. Doch sieht die Wunde gut aus und beginnt sich bereits zu überhäuten.

9. Aug. Wundverlauf ganz normal; die schöne Granulationsfläche verkleinert sich rasch.

12. August. Heute mit Eintritt der Menses neuer Schub von Bläschen auf der rechten Seite derBachwand, begleitet von stechenden Schmerzen. Ferner bemerkt man ein erbsgrosses, ganz oberflächliches Geschwür am äussern Fnde der ersten Operationsnarbe. (Temperaturangaben während dieser Zeit fehlen.)

16. A ugust. Sämmtliche Bläschen haben den früher geschilderten Umwandlungsprocess erfahren und sich in kleine, oberfiächliche Geschwürchen verwandelt, die aber bis heute keinen progressiven Charakter gezeigt haben.

1. Sept. Sämmtliche Geschwüre haben sich heute ohne weiteres geschlossen; doch ist die grosse Narbe an einer kleinen Stelle etwas infiltrirt. Temperaturen in letzter Zeit normal.

2. Sept. Heute Eintritt der Menses, begleitet vow stechenden Schmerzen links vom Nabel.

5. Sept. Während die Temperatur auf $37,8^{\circ}$ stieg, bildete sich unter lebhaften Schmerzen eine kleine Usur auf der 1. Opexationsnarbe. - Die 2. Operationswunde ist beinahe geheilt.

7. Sept. Die Usur von vorgestern verkleinert sich wieder; seither sind die Schmerzen weg, die Temperaturen normal.

8. S e pt. Wieder leichte Schmerzen links vom Nabel.

9. S e p t. Heftiges Stechen daselbst. Temperatur steigt. Am schmerzhaften Orte ist nichts zu sehen.

11. Sept. Beim heutigen Verbandwechsel findet man die 2. Operationswunde überhäutet. - Dagegen präsentirt sich nun $3 \mathrm{Gm}$. links 
und etwas nach oben vom Nabel eine 5 centimesstückgrosse Ulceration auf erhöhter nud gerötheter Haut.

12. Sept. Temperatur gestern Abend auf $38,5^{\circ}$ gestiegen. Heftige Schmerzen an der vorerwähnten Stelle. Die Ulceration hat sich bereits vertieft; im Grunde findet man einen weissen, weichen Belag. Die Ränder sind dermassen gescbwollen, dass das Ganze einen förmlichen Hügel mit einem tiefen Krater darstellt.

13. Sept. 3. Operation. Das Geschwür wird durch eine querovale, reichliche Excision entfernt. Doch wird noch etwas infiltrirtes Gewebe zurückgelassen. Fortlaufende Naht; kein Drain. Listerverband. - Abends Brennen in der Wunde. Temperatur $37,9^{\circ}$. schlecht.

Pat. ist seit den Spitaleiutritte bedenklich abgemagert. Appetit

7. Oct. Seit der letzten Operation ist keine neue Eruption mehr aufgetreten; die Wunde heilte bei normalen Temperaturen Iangsam zu; die Narbe sieht gut aus.

Während der letaten Tage nun machte sich wieder leichtes Abendfieber bemerkbar (doch nie bis $38^{\circ}$ ), und heute Morgen gewahrt man eine Gruppe von 6 rothen Flecken zwischen dem untern Rande der II. und dem obern Rande der IV. Rippe, unmittelbar neben dem rechten. Sternalrande. - Ausserdem hat eine alte Narbe unter dem rechten Rippenbogen an einer kleinen Stelle ihr Epithel verloren.

12. Oct. Die Narbenusur zeigt heute einen speckigen Belag und infiltrirte Umgebung. T. $37,7-38^{\circ}$. Die rothen Fleckchen unverändert.

Eine heute vorgenommene Sensibilitätsprüfung ergab Folgendes: die Sensibilität ist an

Rechts

Stirn, Nase

Wangen

Lippen, Kinn

Brust

Abdomen

Schulter, Ob. - Arm.

Vorderarm

Hand, Finger

Oberschenkel

Unierschenkel

Fuss

Zehen

Genick

Rücken mässig herabgesetzt

ganz geschwunden

mässig herabgesetzt

ganz geschwunden

dto.

erhalten

fast ganz geschwunden erhalten

fast ganz geschwunden

ganz geschwunden

ganz geschwunden

ganz geschwunden erhalten

erhalten bis VIII. Brust-

wirbel; unterhalb geschwonden
Links

mässig herabgesetzt

ganz geschwunden

mässig herabgesetzt

ganz geschwunden

dto.

erhalten

ganz geschwunden

leicht herabgesetzt

ganz geschwunden

?

ganz geschwunden

fast ganz geschwunden erhalten

Gesäss erhalten

erhalten

erhalten

DiePrüfung wurde in Bezug auf Tast-, Orts-, Druck-, Temperatursinn und Schmerzempfindung gemacht; das Resultat war jeweilen für die ver- 
schiedenen Qualitäten das nämliche, - Diejenigen Hautstellen, die gereizt wurden, zeigten eine auffallend rasch eintretende und intensive Gefässinj ection.

16. October. Die auf der Brust entstandenen rothen Flecken sind, ohne Bildung von Bläschen, spontan zurückgegangen; die Stellen, wo sie sassen, sind pigmentirt.

21. October. 4. Operation. Das Geschwür auf der Narbe unter dem rechten Rippenbogen hat sich bei steigender Temperatur (gestern Abend $38,8^{\circ}$ ) rasch vergrössert, namentlich der Fläche nach. Wie gewohnt, sieht man einen weissen, speckigen Belag und einen intensiv gerötheten und geschwollenen Hof. Auffallend sind diesmal im letzteren einige isolirte, kleine Epitheldefecte. Die Schmerzen sind auch jetzt heftig.

Man excidirt heute ein $5 \mathrm{Cm}$. breites und $3 \mathrm{Cm}$. hohes Stück, das die Ulceration und die geschwollene Umgebung enthält. Das Peritoneum wird blos gelegt, aber nicht eröffnet. Schluss der Wunde. Holzwollever band. - Abends weniger starke Schmerzen. - T. $38,1^{\circ}$.

22. October. T. $37,7^{\circ}$.

23. October. T. $37,6^{\circ}$. Eintritt der Periode.

25. October. T. beginnt zu steigen $\left(38,0^{\circ}\right)$. Heute 2 kleine mit Eiter gefüllte Bläschen $4 \mathrm{Cm}$. links vom Nabel.

28. October. T. $38,6^{\circ}$. Während die beiden Bläschen sich inzwischen in braune Fleckchen umgewandelt haben, entstand über dem rechten Rippenbogen, 1 Querfinger über der 4. Operationswunde, ein $3 \mathrm{Cm}$. langes und $2 \mathrm{Cm}$. breites Geschwür mit speckigem Grunde und rother, infiltrirter Umgebung.

2. Nov. Das Geschwür wird mit dem Paquelin cautherisirt. Hernach leichter Abfall der $\mathbf{T}$.

9. Nov. T. bereits wieder gestiegen. Das Geschwür vergrössert sich unter lebhaften Schmerzen.

14. Nov. Leichte Blutung im Geschwürsgrunde.

18. Nov. 5. Operation. Da das Geschwür sich rasch ansdehnte, die Umgebung in grösserer Ausdehnung sich sehr hart infiltrirte, die Schmerzen heftiger wurden, wird heute die Exstirpation des Ulcus vorgenommen. Es wird eine Ellipse von 7:5 $\mathrm{Cm}$. entfernt. Die Infiltration geht bereits so tief, dass ein Stück vom Peritoneum und ein mit diesem verwachsener Netzstrang, nach vorausgegangener Abbindung, mit weggenommen werden muss. Die Schnittfläche des Netzstranges wird versengt; die Wundränder durch versenkte und oberflächliche Suturen ver einigt. Starke Spannung. - Temperatur Abends $38,6^{\mathbf{0}}$.

19. Nov. Heute noch starke Chloroformwirkung. Schmerzen auf der linken Seite des Abdomens. T. $38,7^{\circ}$.

21. Nov. Eintritt der Periode. Temperaturen sind gesunken. Keine neue Eruption. Pat. erholt sich.

26. Nov. T. normal. Wunde liefert etwas übel riechendes Secret; Umgebung leicht gereizt.

29. Nov. Pat. ist schmerz- und fieberfrei. 
10. Dec. Nachdem alles sehr gut gegangen, fiebert Pat. wieder seit einigen Tagen, und heute findet man, fingerbreit neben dem letzt exstirpirten, ein neues, flaches, erbsengrosses Geschwür.

12. D e c. Unter weiterem Steigen der Temperatur heute ein neues, kleineres Ulcus neben dem ron vorgestern.

14. Dec. 6. Operation. Beide Geschwüre, obgleich noch $\mathrm{g}$ anz oberflächlich, werden heute herausgeschnitten, da das immer höher werdende Fieber auf ein bevorstehendes Weiterschreiten derselben hindeutet. Fortlaufende Naht. Abends T. 38, $1^{\text {a }}$.

17. Dec. T. nach der Operation nicht unter $38^{\circ}$ gesunken. Unter stechenden Schmerzen hat sich rechts neben dem Kreuzbein ein nemes Geschwür entwickelt. Heute ist die Periode eingetreten.

22. Dec. 7. Operation. Während Pat. immer höher fieberte, haben sich weitere Geschwüre gebildet in der unmittelbaren Umgebung der letzten Operationswunde; dieselben nahmen sehr rasch den destruiren den Charakter an, indem sie namentlich in die Tiefe vordrangen. Auch zeigt die Wunde stark entzündliche Erscheinungen, die Ränder sind gewulstet, die Umgebung in grosser Ausdehnung geschwollen und hart infiltrirt. Es wird ein grosses Ellipsoid excidirt; doch hat der Process schon sow eit um sich gegriffen, dass es zu eingreifend wäre, alles zu entfernen; ein Theil des infiltrirten Gewebes muss zurückgelassen werden. Um^die grosse Wunde zum Verschluss zu bringen, wird die Haut seitlich unterminirt; 2 Plattennähte vermindern ausserdem die Spannung. Schluss mit Seidensuturen. T. Abends $38,7^{\circ}$.

24. Dec. T. sinkt nicht, immer nahe an $39^{\circ}$.

28. Dec. Vor 4 I'agen Schluss der Periode; T. sank dann etwas, ist aber jetzt bereits wieder auf $38,5^{\circ}$. Verbandwechsel. Alle Nähte durchgeschnitten. Mächtige Wundfläche.

7. Januar 1884. Die Wunde sieht sebr gut aus, verkleinert sich. Pat. ist inzwischen vollkommen schmerzfrei gewesen. T. immer um $38,5^{\circ}$.

9. Jan a ar. Klagt iber Schmerzen nach aussen vou der Wunde. Man sieht dort eine kleine, umschriebene Röthung der Haut.

11. Januar. Beim heutigen Verbandwechsel an Stelle des rothe $\mathrm{n}$ Fleckchens ein kleiner Epithelverlust; Umgebung zeigt weder Röthung: noch Schwellung. Schmerzen dauern fort.

14. Januar. 8. Operation. Da nach anhaltenden Sohmerzen das Geschwür heute einen grau-weissen Belag zeigte, wird es sofort excidirt. - Lineäre Naht.

20. Ja nu ar. Wundränder gangränös geworden; Nähte haben zum Theil durchgeschnitten, zum Theil werden sie entfernt. Ziemlich grosse Wundfläche; die etwas übel riechendes Secret liefert. - T. unverändert, immer um $38,5^{\circ}$.

24. Januar. Die Wunde reinigt sich; diejenige der vorletzten Operation granulirt schön und wird kleiner. Pat. ist in den vergarigenen 10 Tagen schmerzfrei gewesen. 
27. Januar. Eintritt der Menses. Pat. llagt über heftige Schmerzen in der rechten Seite. Beim Verbandwechsel präsentiren sich 2 Geschwürchen in der hinteren Axillarlinie, 2 Querfinger oberhalb der Crista ilei. Sie sind $1 / 2 \mathrm{Cm}$. lang, $3 / 4 \mathrm{Cm}$. breit; der Grund ist blass gelblich, der Rand bereits etwas geröthet und infiltrirt. - Die beiden Operationswunden halten sich gut.

30. Janu ar. Anhaltend heftige Schmerzen. T. heute Morgen $39,3^{0}$. Geschwüre bedeutend grösser; Umgebung stark geschwollen und hart. Die Ulcera werden excidirt - 9. Operation - . Zur Deckung des Substanzverlustes wird diesmal ein Hautlappen unmittelbar oberhalb jenem abpräparirt und mit Nähten fixirt.

4. Februar. T. nach der Operation auf $38,5^{\circ}$ abgefallen und seither auf dieser Höhe geblieben. Schmerzen zurückgegangen. Die Nahtlinie ist an vereinzelten Stellen gangränös geworden.

20. Februar. Neben der Operationsstelle hat sich, ohne sichtbaren Einfluss auf die Temperatur, die sich eonstant um $38,5^{\circ}$ hielt, und ohne Schmerzen zu verursachen, ein kleines Geschwür gebildet. Dasselbe wird. heute entfernt, da es sich auszubreiten begann, - 10. Operation.

25. Februar. Nach der Operation Abfall der T. auf $38,0^{\circ}$. Heute Eintritt der Periode; Schmerzen auf der rechten Seite des Abdomens. T. steigt.

26. Februar. Beim Verbandwechsel findet man die Wunden gut granulirend. Ueber der rechten Fossa iliaca ein $2 \mathrm{Cm}$. langes, $1 \mathrm{Cm}$. breites, noch oberflächliches Geschwür.

27. Februar. 11. Operation. Bei steigender T. und stärkeren Schmerzen hat sich das Ulcus in der gewohnten Weise vertieft und ausgebreitet, weshalb es sofort excidirt wird. Indem man das ganze Infiltrat entfernt, gelangt man bis auf's Peritoneum, das unverletzt bleibt.

6. März. Zwischen Nabel und Processus xi phoides ein $2 \mathrm{Cm}$. langer und $1 \mathrm{Cm}$. breiter braunrother Fleck.

8. März. An der Stelle dieses Fleckes fehlt das Epithel. Ein stecknadellsopfgrosser Epitheldefect wird ferner auf der Invenseite des rechten Oberschenkels bemerkt.

11. März. Ueber beiden Geschwüren ein trockener Schorf von Bismuth. subnitr., das applicirt worden ist. In der Umgebung sammelt sich braunes Pigment an. $2 \mathrm{Cm}$. nach oben und einwärts von der Spina ant. sup. ein neues, oberflächliches Ulcus.

12. März. Dasselbe zeigt heute bereits den bekannten necrotischen Belag und die Infiltration der Umgebung. Es wird daher durch eine 12. Operation exstirpirt. Lineäre Nabt.

17. März. Unter dem linken Rippenbogen ein stecknadelkopfgrosses Bläschen mit hellgelbem Inhalt und leicht geröthetem Hofe. Ueber dem rechten Rippenbogen, etwas einwärts der Mammillarlinie ein kleiner Epitheldefect.

18. März. Auf der linken Seite des Abdomens eine Gruppe von 3 dunklen Schorfen, deren grösster $1 \mathrm{Cm}$. im Durchmesser misst. Sie sind 
von einem rothen Hofe umsäumt. Wie alle frühern beginnenden Efflorescenzen werden sie mit Magist. Bismuth-Brei bestrichen.

19. März. Das vorgestern erwähnte Geschwür zeigt den speckigen Belag und die Infiltration der Umgebung; gleichzeitig ist es grösser geworden. Es wird daher excidirt. - 13. Operation. - Versuchsweise wurde dies Mal ohne Narcose operirt. Während der Excision äusserte Pat. in der That sehr geringe Schmerzen; dagegen war das Ligiren der Gefässe und die Reinigung der Wunde so empfindlich, dass nachträglich etwas Chloroform gegeben werden musste.

24. M ärz. Gestern ein grösserer $\mathrm{E}_{1}$ itheldefect zwischen Spina ant. sup. und Symphyse; heute bereits speckiger Belag und Infiltration. - Excision. - 14. Operation.

26. März. Seit der letzten Menstruation hat sich die Temperatur mit vereinzelten Ausnahmen immer zwischen 38,0 und $38,5^{\circ}$ bewegt. Heute, wie die Menses wieder eintreten, fängt sie wieder etwas zu steigen an (Abends $38,7^{\circ}$ ). Zudem klagt Pat. wieder über Schmerzen auf der rechten Seite der Bauchwand.

28. Närz. T. Abends $38,9^{\circ}$. Unterhalb der letzten Operationsstelle ein ovales Geschwür, dessen Umgebung bereits roth und hart erscheint.Sämmtliche Efflorescenzen auf der linken Seite des Abdomens und am rechten Oberschenkel haben sich ohne weiteres unter dem schorfe geschlossen; braune Pigmentflecke verrathen ihren Sitz.

29. $\mathrm{M} \ddot{\mathrm{r} z} \mathrm{z}, \mathrm{T}, 39,0^{\circ}$.

30. März. T. $39,0^{\circ}$

31. März. 15. 0 p. Da die Infiltration des letzt erwähnten Geschwüres sich ausgedehnt hat, namentlich gegen die Spina hin, so wird heute die Excision vorgenommen. Lineäre Naht, unterstützt durch zwei Plattennähte.

1. April. T. Abends $38,8^{\circ}$.

7. A pril. Die T. hat plötzlich wieder $39^{\circ}$ überschritten. Epitheldefect unter dem rechten Rippenbogen. Alle Nähte der letzten Operation haben durchgeschnitten; grosse Wundfäche.

8. April. Da das gestrige Geschwür sich vertieft, wird es excidirt. - 16. Operation.

13. A pril. Auch hier haben die Nähte durchgeschnitten.

16. April. Schmerzen auf der rechten Bauchseite; flaches Geschwür mit rothem Rande zwischen Rippenbogen und Crista ilei. - Sämmtliche Operationswunden sehen gut aus.

17. April. 17. Operation. Das Geschwür wird heute entfernt.

25. April. 18. Operation. Beim Verbandwechsel findet man heute unmittelbar unter der Operationsstelle vom 17. April an einer Stelle, die schon einige Tage schmerzte, ein neues flaches Geschwür, $3 \mathrm{Cm}$. lang, $1 / 2 \mathrm{Cm}$. breit. Es wird excidirt.

30. April. Menses.

2. Mai, 19. Operation. Zwischen Nabel und Symphyse wird ein frisch entstandenes Geschwür exstirpirt. Zur Deckung der Wundfäche wird die umgebende Haut unterminirt; lineäre Naht. 
6. Mai. Neue Schmerzen, namentlich auf der linken Seite des Bauches. Man bemerkt heute eine kleine Gangrän am Wundrande der letzten Operation, ferner in der linken fossa iliaca, nahe der linea alba ein querovales Geschwür mit einer gelben Kruste und geringer Injection der Umgebung - Infiltration fehlt noch —, endlich eine gleiche Ulceration am Rippenbogen rechts, etwas nach aussen von der Mammillarlinie.

20. Operation. Beide Geschwüre werden ausgeschnitten, das erstere in Form eines Dreieckes mit nachfolgender Naht von den Ecken aus - das letztere in Form einer Ellipse mit lineärer Vereinigung. An der ersten Stelle starke Spannung.

12. Mai. Gestern fand man über der fossa iliaca beider Seiten je ein Geschwür. Bis heate hat sich nur das rechtsseitige vergrössert; es wird daher entfernt - 21. Operation - das andere wird mit Bismath verschorft.

16. Mai. Das letztgenannte Ulcus hat sich bis heute rapid rergrössert; ein neues präsentirt sich über der rechten Hüfte. 22. Operation. Beide Geschwüre werden entfernt; der grosse Substanzverlust an Stelle des ersteren wird mit einem Lappen gedeckt.

20. Mai. Epitheldefect am rechten Rippenbogenrande, zwischen Sternal- und vorderer Axillarlinie.

24. Mai. Wird heute entfernt, da es sich der Fläche nach etwas vergrössert und der Pat. heftige Schmerzen verursacht hat. 23. Operat.

28. Mai. 24. Operation. Ein Geschwür über der linken fossa iliaca wird entfernt.

1. Juni. Sämmtliche Operationswunden sehen gut aus, granuliren zum Theil üppig; der Wundverlauf war bisher äberhaupt immer ein normaler, sofern nichts gegentheiliges in der Krankengeschichte bemerkt wurde.

Die Temperaturen haben sich seit Mitte April sehr constant auf 38,8-39,0 gehalten; zur Zeit der letzten Periode sind sie nicht höher gestiegen.

Heute Schmerzen auf der linken Seite des Abdomens. 3 Querfinger nach links und etwas nach oben vom Nabel ein 1 frankstückgrosses, oberflächliches Gesuhwür; ein zweites, gleiches auf der Spitze des Hautlappens der 19. Operation.

Heute Eintritt der Menses.

3. Juni. Geschwür links oben vom Nabel unter Bismuthschorf geheilt; das zweite ist grösser geworden, wird deshalb excidirt. 25. Oper.

4. Juni. Die Temperatur steigt über $39^{\circ}$.

6. Juni. T. Abends $39,3^{\circ} .2$ frankstïckgrosses Geschwür am rechten Rippenbogen, ausserhalb der Parasternallinie; ein kleineres über der rechten crista oss. ilei.

7. Juni. Das erstere wird, da es heftig schmerzt, und die Temperatur noch immer auf $39,3^{\circ}$ steht, entfernt. 26. ('peration.

10. Juni. Nach der Operation Schwüd der Schmerzen und Abtall der Temperatur auf die gewohute Höhe von $38,8-39,0^{\circ}$. Seit gestern 
hat sich am Rippenbogen, unmittelbar unter dem letzt excidirten, ein neụes, frankstückgrosses Geschwür gebildet mit necrotischem Grunde.

Es wird heute wieder eine Sensibilitätsprüfung vorgenommen. Man erhält dabei ein äusserst buntes Bild; Stellen mit total erloschener Sensiblität wechseln regellos ab mit solchen; die normal empfinden; irgend welche Congruenz mit dem Verlaufe der Hautnerven besteht überhaupt nicht. Es bezieht sich das sowohl auf den Tast- als den Schmerzsinn. Thermische Reize jedoch werden gar nicht als solche empfunden. Die Reaction der Vasomotoren ist auch diesmal eine sehr intensive. Die Patellarreflexe sind eher erhöht.

13. Juni. 27. Operation. Das am 10. Juni erwähnte Geschwür hat sich langsam vergrössert, weshalb es entfernt wird. - In der rechten Lumbalgegend ist ein kleineres Uleus unter dem Schorfe geheilt.

14. Juni. 2 neue Geschwüre über dem Knorpel der sechsten Rippe rechts; sie haben einen rothen Hof, aber noch keinen Infiltrationsring.

15. Juni. Dehnen sich rasch aus. Beginnende Schwellung und Härte der Umgebung.

17. Jun i. Auf dem einen, inzwischen bedeutond grösser gewordenen Geschwüre zeigen sich necrotische Gewebsfetzen. Die Schmerzen sind so unerträglich geworden, dass Pat. bis zur Wirkung einer Morphiuminjection leicht chloroformirt werden muss. - Von einer Operation wird abgestanden, da Pat. nächster Tage die Anstalt verlassen will. Es geschieht dies am 20. Juni 1884.

Wie nachträglich in Erfahrung gebracht wurde, traten wepige Tage nach dem Austritte aus dem Spital neue Geschwüre auf. 12 Wochen $s_{i}$ äter war aber alles geheilt. Später trat noch einmal eine Eruption auf und zwar ausschliesslich auf der linken Sejte des Abdomens. Aus den vorhaudenen Narben liess sich auf eine sehr gutartige Form schliessen, denn jene waren nur oberfläcllich und von höchstens 3. Mm. Durchmesser. - Dagegen bestanden noch während sehr langer Zeit neuralgische Schxnerzen rechts zwischen dem grossen Narbengebiet und der Mamma.

Auch später war noch fast die ganze Körperoberfläche mehr oder weniger analgetisch; selbst im Gesichte war eine verminderte Schmerzempfindung nachweisbar.

Die Periode war auch nach dem Verlassen des Spitals immer regelmässig und schmerzlos. Dagegen sollen während dieser Zeit oft Krämpfe und selbst allgemeine Convulsionen aufgetreten sein. Uebrigens kamen auch in der Zwischenzeit, z. B. während des Religionsunterrichtes solche Anfälle vor.

Im Frühjahre 1888 begann Patientin zu husten; es trat eine rapid verlaufende Lungenphthise auf, der die Kranke am 2. Februar 1889 erlag.

Die exstirpirten Geschwüre wurden in der Anstalt in Alkohol aufbewahrt; einige davon wurden dem pathologischen 
Institute in Zürich überwiesen, wo sie Herr Professor Klebs einer eingehenden Untersuchung würdigte. Der Fall ist im neuesten Werke dieses Autors erwähnt; ${ }^{1}$ ) wir lesen dort Folgendes:

...... Es tritt zunächst Necrose ein, welche von Gewebsneubildung gefolgt ist; die letztere ist um so bedeutender entwickelt, je länger das Uebel besteht. Schliesslich erlangen die auf diese Weise entstehenden Geschwüre ron kraterartigem Aussehen geradezu den Charakter eines Sareoms; indem sie ungeachtet der Gewebswucherung stets weiter in die Tiefe vordringen, können . . . Perforationen der die Körperhöhlen begrenzenden. Weichtheile, hier der Bauchdecken stattfinden. Die jüngsten Geschwüre dagegen zeigen kaum Spuren von Gewebswucherung. Ich habe mich in dem erwähnten Falle durch die mikroskopische, wie durch die bacteriologische Untersuchung überzeugen können, dass Bacterien bei diesem Vorgange keine Rolle spielen. Schwieriger ist die Frage zu entscheiden, durch welche Ursachen die Necrose hervorgerufen wird. Wenn dafür die Hinfälligkeit des neugebildeten Gewebes in Anspruch genommen wird, so ist damit nicht viel mehr als eine Umschreibung des thatsächlichen Verbältnisses geliefert; es bleibt zu entscheiden übrig, worauf diese Hinfälligkeit beruht. In den weiter fortgeschrittenen Fällen, in denen sarcomartige Wucherungen mit sehr weiten Blutgefässen vorhanden sind, kann eine Verlegung dieser durch Anhäufung weisser Blutkörperchen, eine weisse Thrombose nachgewiesen werden; allein dieselbe ist nicht ausgedehnt genug, um als alleiniger Grund zu gelten, und fehlt auch in den frühereu Entwicklungsstadien. So kann auch hier per exclusionem an nichts anderes, als an einen gestörten Nerveneinfluss gedacht werden. Leider ist es mir nicht gelungen, an den zahlreichen exstirpirten Geschwüren über diesen Punkt ins Klare zu kommen. Doch besteht eine auffallende Schwierigkeit in dem Nachweis von Nerven überhaupt in den exstirpirten Hautstücken, und vermuthe ich deshalb, dass auch hier solche entweder fehlen oder sehr mangelhaft entwickelt sind, zumal das Auftreten des Processes gänzlich mit

t) Klebs, Die allg. Pathologie, II. Theil, Jena 1889. Pag. 38 und 39. 
demjenigen des gewöhnlichen Herpes zoster übereinstimmt, bei welchem nunmehr durch eine Reihe guter Beobachtungen tiefe Veränderungen in den Nervenstämmen nachgewiesen worden sind."

Ich habe nachträglich einige der Geschwüre, namentlich frische, an Paraffinschnitten untersucht. Leider waren, namentlich an der einzelnen Zelle, keine Details mehr zu sehen, da. die Präparate durch den langen Aufenthalt im Alkohol stark geschrumpft, und die mikroskopischen Bilder durch krystallinische Niederschläge vielfach verwischt sind. Trotzdem dürfte der histologische Befund erwähnenswerth sein.

Sehen wir uns den Querschnitt eines 3-4 Tage alten, etwa $3 / 4 \mathrm{Cm}$. breiten Geschwüres an, zu einer Zeit, wo es bereits beginnt weiter zu wuchern. An einem Ende sehen wir noch das normale Epithellager; bald aber verändert es sich; die oberflächlichen Zellen des Rete Malpighi verlieren mehr und mehr ihre Färbbarkeit und ihre Kerne; es sieht aus, als ob die Epidermis sich auf Kosten des Rete verdicken würde. Auf einmal reisst diese Schicht ab; die Spitzen der Papillen liegen. bloss, und wir finden annähernd normales, kernhaltiges Epithel nur noch zwischen den einzelnen Papillen. Gegen das Centrum des Geschwürs hin, wo sich die Papillen mehr und mehr verkürzen, fehlt es ganz, oder ist nur noch durch homogene, kernlose, mit Eosin intensiv gefärbte Pfröpfchen angedeutet. Doch findet man in einzelnen Schnitten auch gegen das Geschwürscentrum hin zuweilen noch Ansammlungen schön gebildeter Epithelien, nämlich da, wo Haare hervortreten. Am Rande der Ulceration bemerkt man zwischen den Zellen des Rete vereinzelte Leucocyten. - Das Corium bildet nach aussen schöne Papillen; vom Geschwürsrande an werden aber letztere bald kleiner und kleiner, und bald findet man an der von Epithel entblössten Oberfläche nur noch seichte Einkerbungen, welche die Basen der einzelnen Papillen von einander trennen. - Die Cutisgefässe sind weit, und sämmtlich von einer sehr dichten kleinzelligen Infiltration umgeben; die Gefässwände selbst sind stellenweise von Leucocyten stark durchsetzt. Das Lumen ist. entweder leer, oder enthält Ansammlungen von weissen Blutkörperchen, die aber gewöhnlich die Oeffnung des Gefässes 
nicht ganz ausfüllen; indess fand ich sie ausuahmsweise schon in einzelnen frischen Geschwüren in so grosser Anzahl, dass ich nicht daran zweifle, dass sie zu einem gänzlichen Verschlusse der betreffenden Gefässe führten. Bemerkenswerth ist auch die starke Infiltration um die Schweiss- und Talgdriisen, sowie um die Haarfollikel herum. In den Interstitien zwischen den dicken, derben Fasern der Cutis ist die Zabl der Rundzellen eine relativ sehr mässige; dichter angesammelt findet man sie erst seitwärts, d. h. jenseits des Geschwürsrandes, und in den tieferen Schichten, im subcutanen Fettgewebe und dem darunter liegenden fascialen Gewebe. Die Hautpapillen sind nur in der unmittelbaren Umgebung des Geschwürs, und auch hier nur an ihren Spitzen diffus infiltrirt; daneben sind allerdings ihre Gefässschlingen meistens von Leucocyten dicht umlagert. - An einzelnen Stellen bemerkt man im Corium structurlose Massen, die sich mit Eosin dunkler färben und eine Unzahl zersprengter Kernfragmente in sich schliessen; an einzelnen Orten bekommt man auch kurze Stücke von dicken Bindegewebsfasern zu Gesichte. Diese Massen liegen entweder isolirt in den tieferen Schichten der Cutis, oder sie senken sich trichterartig von der Oberfäche her in die Lederhaut hinein. Offenbar stellen sie den Beginn des necrotischen Zerfalles dar. - Der Befund an älteren Geschwüren ist im obigen Citate geschildert.

Dies ist die ziemlich weitläufige Krankengeschichte unserer Patientin; sie lässt sich kurz etwa folgendermassen resumiren:

Ein 16jähriges Fabrikmädchen, dürftig genährt, von sehr beschränkter Intelligenz, tuberculös belastet, in schwerem Grade hysterisch, leidet seit 4 Jahren an einem ulcerösen Hautausschlage auf der rechten Seite des Abdomens. Als Residuer desselben findet man totale Anästhesie und ausgedehnte, zum Theil vorspringende Narbenstreifen und Pigmentationen im. Gebiete, wo sich die Krankheit abgespielt hat. Letztere tritt neuerdings auf, und die nun folgende 2jährige Beobachtung der Patientin lässt folgenden Charakter des Exanthems fest: stellen. Das erste, was das Auge sieht, ist ein rother Fleck, der theils auf Gefässdilatation, theils auf Blutextravasation beruht. Es folgt eine leichte Entzündung des Coriums; es kommt 
zu seröser Transsudation und zur Bildung eines hellen Bläschens auf gerötheter Basis. Dieses selbst vergrössert sich; in sein Inneres findet eine Blutung statt; endlich trocknet es ein zu einem Schorfe, welcher sich unter leichter Eiterung abstösst. Jetzt haben wir einen einfachen Epitheldefect vor uns. Sogleich, oder im Verlauf von wenigen Tagen tritt eine entzündliche Infiltration der Umgebung auf; diese Infiltration greift immer weiter und weiter um sich; aber während die Peripherie weiter wuchert, tritt im Centrum Gangrän ein, und auf diese Weise kommt es zu mächtigen Substanzverlusten, die im Stande sind, die Bauchböhle zu perforiren. - Das erythematöse und resiculäre Stadium sind jeweilen von sehr kurzer Dauer, und da das kranke Gebiet meistens unter einem Verbande liegt, so ist es immer einem glücklichen Zufalle zu rerdanken, wenn man dieses füchtige Stadium zu Gesichte bekommt.

Der geschilderte Verlauf stellt die schlimmste Form dar; glücklicher Weise nimmt aber nicht jede Efflorescenz diesen Verlauf; im Gegentheil, der Process kann in jedem Stadium rückgängig werden; die rothen Flecke können verschwinden, die Bläschen sich abstossen, ohne eine Narbe zu hinterlassen; viele der Epitheldefecte heilen rasch unter dem Schorfe, oder offen, und man sieht später nur eine kleine, flache Narbe; ja, wenn bereits Wucherung und Gangrän aufgetreten ist, so kann es noch frühzeitig zur Rückbildung und Ausheilung kommen.

Der Process geht nicht ohne subjective Beschwerden vor sich ; heftige Neuralgien gehen der Eruption unmittelbar voraus, oder begleiten diese; sie können aber ausnahmsweise auch ganz feblen. Als die Hautaffection einmal definitiv zur Ruhe gelangt ist, hat die Kranke noch längere Zeit an jenen Neuralgien zu leiden.

Jede Eruption ist von Fieber begleitet, doch bleibt letzteres mässig; wenn die Eruption einen gutartigen Verlauf nimmt; erst wenn es zu Gangrän und damit zur Resorption septischer Stoffe kommt, steigt die Temperatur höher, selbst bis $40^{\circ}$.

Was die Localisation der Efflorescenzen betrifft, so halten sich diese im Allgemeinen an ein Areal, das oben rom Rippenbogen, unten von der Crista ilei und dem Lig. Pouparti, hinten won der Wirbelsäule und vorn von der Linea alba begrenzt ist; 
ausnahmsweise werden diese Grenzen mehr oder weniger weit iiberschritten.

Die Efforescenzen treten meist disseminirt auf; oft aber stellen sie sich zu kleinen Gruppen zusammen.

Der Verlauf ist ein exquisit chronischer, denn er erstreckt sich auf einen Zeitraum von ungefähr 6 Jahren. Wenn wir der Patientin glauben dürfen, so war er in dèn ersten 4 Jahren ein continuirlicher; in unserer Beobachtung dagegen treten, Anfangs wenigstens, Remissionen von oft vielen Wochen auf. In den letzten $3 / 4$ Jahren nimmt dann der Process wieder einen continuirlichen Verlauf; es vergeht kaum eine Woche, wo nicht mehrere Schübe auftreten. Nach dem Austritt aus dem Spital tritt die Krankheit wieder in ein Stadium der Remission, mit dem sie dann endlich abschliesst.

Ich halte diese Krankheit für einen aty $\mathrm{p}$ is chen Z o s ter.

Nach Kaposi bezeichnen wir jene Krankheitsform als Herpes zoster, welche nach dem Typus des Herpes, das ist mit acut auftretenden Bläschengruppen an einer Körperhälfte, höchst selten an beiden, sich localisirt, und mit seiner Eruption die durch die Nerven vorgezeichnete anatomische Richtung einhält.

In unserem Falle ist die charakteristische $\mathrm{L}$ oc al is a ti on so sehr ausgesprochen, dass man aus diesem einzigen Symptome ohne weiteres auf einen Zusammenhang zwischen Hauteruption und Nervensystem schliessen muss. Schon bei der Aufnahme der Patientin fiel die streifenförmige Anordnung einiger Narben und ihr Parallelismus mit dem Verlaufe der vorderen Aeste der Dorsal- resp. Lumbalnerven auf. Besonders bervorzuheben ist aber, dass sich die Krankheit, mit ganz wenigen Ausnahmen, auf einem Hautbezirke abspielte, der genau der Ausbreitung des 8.-12. Dorsalnerven, sowie einiger Hautnerven, die vom 1. und 2. Paare des Plexus lumbalis herstammen, entspricht. In der That wissen wir aus der Anatomie, dass die hinteren Aeste der 5 letzten Dorsal- und der Lumbalnerven die Haut der Lendengegend und der seitlichen Bauchwand innerviren. Die vorderen Aeste der genannten Dorsalnerven verzweigen sich in der vorderen Abdominalwand; die vorderen Aeste der 
Lumbalnerven dagegen formiren den Plexus lumbalis; vom ersten Paare desselben gehen die Nervi abdomino-genitales superior et inferior ab, um die unteren Partien der vorderen Bauchwand nnd den Oberschenkel zu innerviren, - vom zweiten Paare die Nervi femoro-cutaneus und inguino-cutaneus internus; ein Ast des ersteren verliert sich in der regio glutäalis, der letztere in der oberen Hälfte der Vorderfläche des Oberschenkels und in den Genitalien.

Wenn man den ganzen Verlauf der Krankheit ins Auge fasst, so wird auffallen, dass die Eruptionen nicht regellos, sondern in einer bestimmten Ordnung auftreten. Die Krankheit beginnt in der Lumbalgegend, mithin im Gebiete der hinteren Aeste der Dorsal- und Lumbalnerven; dann schreitet sie stetig weiter nach vorn; sind einmal die vorderen Aeste der Lumbalnerven ergriffen, so treten Efflurescenzen in der Glutäalgegend und am Oberschenkel auf, entsprechend der Ausbreitungsweise gewisser sensibler Nerven des Plexus lumbalis, wie dies oben auseinandergesetzt ist. Endlich in der letzten Zeit der Beobachtung spielt sich der Process meistens nahe der Medianlinie oder an der oberen resp. unteren Grenze des kranken Bezirkes ab. Eruptionen kommen zwar auch später noch auf früher befallenen Stellen vor, doch ist dies die Ausnahme. - Gewöhnlich lassen sich die, in einem bestimmten Zeitraume auftretenden Geschwüre der Mehrzahl nach auf einen oder mehrere ganz bestimmte Nerven zurückführen. So z. B. treten im Februar und März 1884 eine Reihe von Geschwüren auf den Bauchdecken rechts unten und gleichzeitig am Oberschenkel auf; also genau im Rayon der Nervi abdomino-genitales inf. et sup. Die Eruption vom Mai und Juni desselben Jahres bildet einen langen Streifen, der mit dem Rippenbogen verläuft, mithin einem Intercostalnerven entspricht. Im gleichen Zeitraume treten ausserdem eine grössere Anzahl von Geschwüren an eng umschriebener Stelle zwischen Nabel und Symphyse auf u. s. w.

Auffallend ist die Thatsache, dass mehrmals die Mittellinie überschritten wurde; ja, nach Angabe der Patientin sass das zuletzt aufgetretene Exanthem ausschliesslich auf der linken Hälfte des Abdomens. Sollen wir deshalb einen 
doppelseitigen Zoster annehmen? Es ist möglich, dass wir es mit dieser ziemlich seltenen Form zu thun haben; dabei bleibt aber doch auffällig, dass die Eruption immer nahe der Mittellinie sass, dass auf den rückwärts gelegenen Partien nie eine Efflorescenz bemerkt wurde, und dass die linksseitige Eruption sich zeitlich und örtlich direct an die rechtsseitige anschloss. Ein Ueberschreiten der Medianlinie kommt beim Herpes zoster häufig vor, was auch leicht erklärlich ist, da ja die Hautnerven. der einen Seite sich mit den gegenüberliegenden verflechten, also ebenfalls über die Mediana hinausreichen; ob das aber bis auf 5 und $6 \mathrm{Cm}$. weit geschieht - und um so viel waren einzelne Efflorescenzen von der linea alba entfernt - ist mir unbekannt.

Sehr bemerkenswerth ist das plötzliche Auftreten einer abortiv verlaufenden Eruption im Gebiete des 3. bis 4. rechten Intercostalnerven.

Was die die Hautaffection begleitende Neuralgie betrifft, so war sie, wenigsteus während der Zeit der ärztlichen Beobachtung, ein fast constantes Symptom, so constant, dass ihr Auftreten ohne weiteres auf die unmittelbar bevorstehende Eruption einer neuen Efflorescenz hinweisen musste, und in der That die Erwartung selten täuschte. Im Allgemeinen war die Neuralgie sehr heftig, zuweilen so unerträglich, dass man, um Linderung zu schaffen, zu einem operativen Eingriffe genöthigt war. Sie überdauerte, wie wir gehört haben, den cutanen Process noch längere Zeit.

Auf das Bestehen ron Druckpunkten ist uicht geachtet worden.

Sensibilitätsstörungen bestanden insofern, als der kranke Bezirk absolut anästhetisch war. Doch ist die Beobachtung in dieser Beziehung nicht ganz rein, denn es bestanden auch anderswo schwere Gefühlsstörungen als Folge der Hysterie.

Das zweite Postulat der Diagnose Herpes zoster ist der Nachweis acut auftretender Bläschengruppen, resp. von Veränderungen, die diesen genetisch äquivalent sind, denn die Bläschen können in Folge besonderer anatomischer Verhältnisse überhaupt nicht zur Ausbildung gelangen. Dies kann einmal stattfinden bei sehr dünner, zarter Epidermis, wie solche 
z. B. die neugebildeten Narben bedeckt. Sobald es an solchen Stellen zur Bläschenbildung kommen soll, d. h. sobald eine seröse Exsudation unter die Epidermis stattfindet, platzt letztere, indem sie dem Drucke der sich sammelnden Flüssigkeit nicht Stand zu halten vermag. - Die Bildung von Bläschen kann aber noch auf andere Weise verhindert werden. Wir werden weiter unten sehen, dass das Primäre beim Zoster eine Necrose des Rete Malpighi ist. Wenn nun in besonders intensiren Fällen nicht, nur dieses, sondern gleichzeitig auch die oberflächlichste Schichte der Cutis necrotisirt, so werden damit diejenigen Capillaren, welche das Exsudat für die Herpesbläschen zu liefern hätten, zerstört, und aus den tieferen Gefässen kann das Serum nur schwer unter die Epidermis gelangen, weil jene durch das necrotische Corium von dieser getrennt sind. Auf diese Weise wird die Bläschenbildung ebenfalls gleich im Beginne gehemmt; dass es sich aber doch um eine solche handelt, kann dann aus dem makroskopischen Flächenbilde oft nicht mehr ersehen werden, und nur der mikroskopische Querschnitt kann uns noch zur richtigen Deutung. des Processes verhelfen.

Dass es sich in unserem Falle um einen herpetischen Ausschlag handelte, kann nicht bezweifelt werden, denn man hat mehrmals typische Bläschen zu beobachten Gelegenheit gehabt. Wenn das nicht bei jeder Efflorescenz der Fall war, so lag das an dem Umstande, dass das kranke Gebiet meistens verbunden war, und zudem das vesiculöse Stadium ein sehr flüchtiges war. In dieser Beziehung ist der Fall analog dem Herpes der Cornea, bei dem bekanntlich der Arzt meistens Geschwüre und ausserordentlich selten ein Bläschen zu sehen bekommt. - Endlich mag es aus dem oben angeführten Grunde oftmals überhaupt nicht zur Entwicklung von Bläschen gekommen sein.

Auffallend ist, dass relativ selten Bläscheng r up pen auftraten; solche sind zwar einige Male constatirt worden; gewöhnlich aber traten die einzelnen Efflorescenzen isolirt auf. Doch scheint sich eine Tendenz zur Gruppenbildung darin zu verrathen, dass sich die Geschwüre, die innerhalb einer bestimmten Zeit erschienen, an einen eng umschriebenen Bezirk hielten. 
Im Anschlusse an diese Bemerkungen bezüglich der Diagnose möchte ich noch auf einige Eigenthümlichkeiten hinweisen, die unsere eigene Krankengeschichte bietet.

Wir erinnern uns, dass zu Beginn des Spitalaufenthaltes der Patientin ein grosses Geschwür entstand, das an der Peripherie rasch weiter wucherte, während das Centrum dem Zerfall anheimfiel. Klinisch stimmte dieses Verhalten ganz und gar mit demjenigen eines Sarcomes überein; ja, auch die mikroskopische Untersuchung lieferte ein Bild, das der Structur eines Rundzellensarcomes zu entsprechen schien. Angesichts des früheren Verlaufes der Krankheit musste man allerdings schon damals den neurotischen Ursprung des Leidens voraussetzen; dagegen sah man sich sehr zur Anməhme gedrängt, es möchte sich eines der Geschwüre in eine maligne Neubildung nmgewandelt baben. Die Entstehung von bösartigen Tumoren auf dem Boden ursprünglich gutartiger Geschwüre ist ja heute, trotz Cohnheims Autorität, eine Thatsache, Dank einer Reihe von genauen Beobachtungen. Im Verlaufe der Krankheit musste diese Voraussetzung dann fallen gelassen werden; es stellte sich heraus, dass die Nenbildung rein entzündlicher Natur war. Aber welche Momente verschulden es, dass, während einzelne Geschwüre ohne weiteres durch Granulationsbildung, selbst unter dem Schorfe ausheilten, bei andern eine so intensire entzündliche Reaction auftrat? In diesem Verhalten liegt eine ganz besondere Eigenthümlichkeit des Falles. Entzündung und nachfolgende Gangrän von herpetischen Efflorescenzen ausgehend sind schon beobachtet worden. So berichten Hall npeau und Tuffier ${ }^{1}$ ) über einen Herpes des Gesichtes, der Mundhöhle und des Schlundes, wo sich im Bereiche der Schleimhaut kleine Geschwüre bildeten, die sich secundär inficirten und zu ausgedehnter Gangrän und schliesslich zum 'Tode des Individuums führten. - Auch in unserem Falle musste man ja gewiss in erster Linie an eine Infection von den Ulcerationen a us denken. Allein wir haben gesehen, dass die diesbezüglichen Untersuchungen vollkommen negativ ausfielen. Vorläufig bin ich nicht im Stande, mir irgend eine Vorstellung zu machen

1) Union médicale. 1882. Nr. 80. 
über die Ursache dieser fortschreitenden Entzündung. Vielleicht sind es jene nämlichen, uns ebenfalls noch unbekannten Factoren, die das Weiterwuchern gewisser Geschwülste bedingen.

Wir haben uns weiter die Frage vorzulegen, a uf was die im Centrum der Entzündungsherdeauftretende Gangrän beruht. Die Ursache derselben kann in einer Functionsstörung der trophischen Nerven, oder aber der localen Circulation liegen; die Circulationsstörung selbst kann endogenen Ursprungs sein, oder von den Vasomotoren abhängen. Wir haben nun bei den im Vorigen citirten Fällen gesehen, dass die Necrose immer auf allen Punkten des erkrankten Bezirkes zugleich auftrat; sie ist nie, wie in unserem Falle, allmälig von einem Orte aus auf die Nachbarschaft übergegangen. Dieses Verhalten war bei allen Efflorescenzen so constant, dass es ein charakteristisches Symptom directer nervöser Necrose zu sein scheint. Gangrän auf vasomotorischer Störung basirend ist ebenso unwahrscheinlich, hat man doch niemals am Geschwürsgrunde jene charakteristischen, durch die localen Circulationsstörungen bedingten Veränderungen constatirt, d. h. die locale Anämie und Asphyxie. Wir sehen uns demnach genöthigt, das ursächliche Moment der Necrose in irgend einer localen Störung des Kreislaufes zu suchen. Die mikroskopische Untersuchung hat uns in dieser Hinsicht nicht ganz im Stiche gelassen; wir haben in vielen Blutgefässen Ansammlungen ron Leucocyten gefunden, stellenweise in so hohem Grade, dass eine vollständige Thrombosirung des Gefässes resultirte. Wir können uns zwar kaum vorstellen, dass die dadurch verursachten Circulationsstörungen genügen könnten, um ein normales Gewebe zum Absterben zu bringen; dagegen ist es nicht undenkbar, dass ein durch die entzünaliche Infiltration bereits hochgradig alterirtes Gewebe eine solche Beeinträchtigung seines Kreislaufes nicht mehr verträgt.

Eine weitere bemerkenswerthe Eigentbümlichkeit unseres Falles liegt ferner in seinen Beziehungen zur Menstruation. Verzeichnet man die Temperaturen auf einer fortlaufenden Curve und notirt auf derselben gleichzeitig die verschiedenen Eruptionen und die Tage der Menstruation, so fällt sofort in die Augen, dass beinahe jedesmal mit der Periode eine oft 
sehr beträchtliche Steigerung der Temperatur und Hand in Hand damit eine neue Eruptjon, respective eine fortschreitende Infiltration von schon bestehenden Geschwüren aus, stattfindet, oder doch, wie in der letzten Zeit der Beobachtung, wo unausgesetzt neue Efflorescenzen ausbrachen, die Eruptionen zur Zeit der Menses zahlreicher sind, als in der Zwischenzeit. In den übrigen Fällen von gangränösem Zoster ist ein solches Zusammentreffen nie beobachtet worden. Dagegen finden sich in der. Literatur mehrfach Beobachtungen von sog. Menstrualexanthemen, anderen, verschiedenen Hautkrankheiten, deren Auftreten jeweilen mit der Periode coincidirte.

Nach Angabe der Patientin sind während der Menses mehrmals Blutungen aus den Geschwüren aufgetreten; äbnliches wurde auch einige Male in der Anstalt seibst beobachtet. Man hat diese Hämorrhagien selbstverständlich nicht mit den sog. vicariirenden Blutungen auf gleiche Stafe zu stellen, sondern man wird sie mit dem zur Zeit der Menstruation gesteigerten gaugränösen Zerfall der Geschwüre in Zusammenhang zu bringen haben, welch letzterer eben durch Eröffnung von Gefässen die directe Ursache der Blutungen war.

Sehr auffallend ist weiter die lange Dauer der Krankheit. Während der Herpes zoster normaliter innerhalb 2 bis 4 Wochen abläuft, erstreckte er sich hier über mehrere Jahre, aber nicht in continuirlicher Weise, denn es traten zu Anfang des Spitalaufenthaltes, wie dann auch später wieder, längere щnd vollständige Ruhepausen ein; der ursprünglichen Erkrankung sind also mehrfache Recidive nachgefolgt. Diese recidivirenden Zosteren sind früher als extrem selten geschildert worden; ja, man hat diesen Umstand selbst als Beweiswittel für die Theorie der Infectiosität der Krankheit in Anspruch genommen. Indess hat im Jahre $1886 \mathrm{Epstein}{ }^{1}$ ) eine ganze Reihe von Zosterrecidiven in der Literatur gefunden, und es scheint, dass sich diese Fälle, seit man ihnen mehr Aufmerksamkeit schenkt, rasch vermehren. Uebrigens betont Lesser ${ }^{\mathbf{9}}$ ) mit Recht, dass es nachträglich oft schwer ist, einen voraus-

1) Zoster u. Herpes fac. u. genit. Vierteljahrschr.f. Derm. u. Syph. 1886.

2) Beiträge zur Lehre vom H. z. V. A. Bd. 86. 1881. 
gegangenen Zoster zu diagnosticiren, da er eben in der überwiegenden Mehrzahl der Fälle abläuft, ohne irgend welche Symptome zu hinterlassen.

Es soll endlich noch erwähnt werden, dass sich hier, wie bei den meisten schweren, gangränösen Formen, Narbenkeloide bildeten, die oft eine sehr beträchtliche Grösse erreichten.

Im Anschluss hieran möchte ich einige Bemerkungen über die Aetiologie einflechten. - Seit den Untersuchungen von Bärensprung's, deren Resultat er zu Anfang der 60. Jahre in den Charité-Annalen (IX) publicirt hat, wissen wir, dass die Ursache des Herpes zoster in einer Läsion des Nerrensystemes. liegt, speciell jener Nervenelemente, die die Ernährung der Haut reguliren. Aber wie sollen wir uns den Zusammenhang zwischen einer solchen Verletzung und den localen Erscheinungen auf der Haut vorstellen? Diese Frage ist heute noch schwer zu lösen; das zeigen uns schon die mannigfachen Antworten, die sie gefunden hat. - So hat Friedrich, ) der im Herpesbläschen den Ausdruck einer umschriebenen Hantentzündung sieht - letztere unmittelbar hergeleitet von einer descendirenden Neuritis - begründeten Widerspruch gefunden, und neuere Autoren, wie $\mathrm{Bohn}{ }^{2}$ ) und Dubler, ${ }^{3}$ ) haben für diese Theorie auch keine beweiskräftigen Argumente beigebracht.

Ebensowenig haben Eulenburg ${ }^{4}$ ) und Landois ${ }^{5}$ ) ihre Ansicht aufrecht erhalten können, als sie die Herpeseruption als das Product einer neuroparalytischen Hyperämie aufgefasst wissen wollten.

We ige $\mathbf{r t}^{6}$ ) vermuthet, dass unter dem Einflusse einer nervösen Störung oberflächliche Gewebstheile absterben, wodurch der Invasion von infectiösen Elementen das. Thor geöfnet würde. Solche Mikroorganismen sind aber in den meisten Fällen nicht gefunden worden.

1) Progressive Muskelatrophie. 1873.

2) Hautkrankh. i. Gerharts Handbuch d. Kinderkrankh. 1883.

3) Neuritis bei Herpes zoster. J. D. Basel 1884.

4) Berl. kl. Wochenschrift. 1867.

5) Wien. med. Wochenschr. 1867.

6) Eulenburgs Realencykl. IV. Art. „Entzündung“. 
Les ser ${ }^{1}$ ) findet nun mit Recht, dass es der Annahme einer Secundärinfection überhaupt nicht bedürfe zur Erklärung der Entzündung. Er glaubt, wie Weigert, an eine primäre Zellnecrose, und zwar im Rete Malpighi; das necrotisirte Gewebe nun soll als Fremdkörper die umgebende Cutis reizen und in Entzündung versetzen. - Diese Anschauung hat allerdings durch mikroskopische Untersuchungen, die in den Frähstadien der Efflorescenzbildung unternommen wurden, eine solide Basis gewonnen, indem von mehrfacher Seite Necrotisirungen im Rete als erste Veränderungen konnten nachgewiesen werden (Doutrelepont, ${ }^{2}$ ) Lesser. ${ }^{3}$ )

Dass unter dem Einflusse des Nervensystemes Zellnecrose eintreten kann, wird heute kaum mehr bestritten werden. Wenn wir auch über die intimeren Vorgänge, die dabei von statten gehen, noch nicht unterrichtet sind, so haben doch verschiedene Thatsachen, die wir der neueren Pbysiologie und Anatomie verdanken, den Weg zu einem besseren Verständnisse angebahnt. So wissen wir, dass letzte Ausläufer von Nerven in Epithelzellen eindringen und hier endigen. Anderseits ist uns bekannt, dass solche Nervenfasern die Secretion gewisser Drüsen beherrschen, und da es sich hier nicht um blosse Filtration handelt, so müssen wir annehmen, dass jene Fasern im Stande sind, die chemischen Vorgänge im Zellinnern zu beeinflussen. Können wir uns nun nicht vorstellen, dass, wenn diese Nervenelemente ihre Function einstellen, auch die chemischen Umsetzungen in der Zelle sistiren und letztere damit dem Tode anheimfällt?

Sollten diese Erörterungen sich als richtig erweisen, so müssten wir mithin die Zosterefflorescenzen als die Folge einer Sistirung nervöser Functionen, als eine sog. Ausfallserscheinung auffassen, wie das schon vor längerer Zeit $\mathrm{Vulpian}{ }^{4}$ ) gethan hat. Und in der That finden nun diese theoretischen Deductionen in verschiedenen Thatsachen eine solide Basis.

Einmal im Verhalten der Sensibilität. Der Zostereruption geht sehr oft eine prodromale Neuralgie und Hyperästhesie

I) V. A. Bd. 86. 1881 .

$\left.{ }^{2}\right)$ Vierteljahrsschr. f. Derm. u. Syph. 1886. 2. p. 179.

3) V. A. Bd. 86. 1881.

${ }^{4}$ Lecons sur les Vasomoteurs. 
voraus. Ist das Exanthem einmal ausgebrochen, so macht letztere sehr gewöhnlich einer Herabsetzung der Empfindung, selbst völliger Anästhesie Platz. Wir können uns die Sache folgendermassen vorstellen. In Folge der Nervenläsion (Blutang, Entzündung etc.) wird der Nerv in einen Zustand dauernder Reizung versetzt, der sich durch die Neuralgie und Hyperästhesie manifestirt. Führt dann früher oder später die Läsion zur Degeneration des peripheren Nervenendes, so wird mit diesem Momente die Sensibilität des entsprechenden Hautbezirkes herabgesetzt, oder selbst ganz aufgehoben, je nach der Zahl der leitungsunfähig gewordenen Nervenfasern. Erfahrungsgemäss tritt nun der Ausschlag gerade zu der Zeit auf, wo die Hyperästhesie in Anästhesie übergeht, dann also, wenn der sensible Nerv sein Leitungsvermögen verliert. Mit dem sensiblen Nerven werden aber voraussichtlich auch die die Ernährung regulirenden Fasern zu Grunde gehen, da ja beide Systeme in einen Strang vereint sind, wenn sie überhaupt nicht identisch sind.

Wenn ferner in ganz frischen Fällen von. Herpes zoster (W y s s, $\left.{ }^{1}\right)$ Le s s e ${ }^{2}$ ) Degeneration aller peripheren Nervenfasern gefunden wurde, so drängt uns das ebenfalls zur Annahme, dass das Hautexanthem nicht das Product eines Nervenreizes, sondern vielmehr einer, Leitungsunfähigkeit ist. - Wenn erst längere Zeit nach der Eruption die Untersuchung vorgenommen werden kann, und dann nur gesunde Fasern angetroffen werden, so beweist das nichts gegen unsere Auffassung, denn das periphere Nervensegment kann sich inzwischen regenerirt haben. Es kann dies geschehen, sobald das lädirende Moment, die Entzündung, Blutung etc. zurückgegangen ist, vorausgesetzt, dass das Spinalganglion nicht ganz zerstört ist.

Endlich muss ich noch aufmerksam machen auf das völlige Uebereinstimmen des Herpes zoster der Cornea mit der sog. neuroparalytischen Keratitis, jener Erkrankung der Hornhaut, die bei Leitungsunfähigkeit des I. Trigeminusastes auftritt.

Wir gelangen nun zur weiteren Frage nach der Art und dem Sitze der Nervenläsion. Es ist bekannt, dass v. Bärensprung auf rein theoretischem Wege zu dem Schlusse kam,

1) Arch. der Heilk. XII. 1871. n. Dubler 1.. c.

2) 1. c. 
dass fast immer die Intervertebralganglien der Sitz der Erkrankung sein müssen, und daraufhin vorgenommene Untersuchungen - von ihm selber sowohl, als von einer Reihe anderer Forscher - schienen diese Ansicht durchaus zu bestätigen, denn man fand fast immer an den Spinalganglien pathologische Veränderungen, meist Blutungen, seltener Entzündungen, Neubildungen etc. Bei diesen Untersuchungen sind aber gewöhnlich die Ganglien allein untersucht worden, während man das Verhalten der peripheren Nerven ganz unberücksichtigt liess. Als man nun in neuerer Zeit auch diese letzteren zu prüfen begann, da fanden sie sich allerdings oft erkrankt, während die Ganglien entweder ganz unversehrt, oder doch nur secundär betheiligt waren.

So viel dürfte heute wobl feststehen, dass die Erkrankung in den allermeisten Fällen den peripheren Nerven (inclusive das Ganglion) betrift, dass sie aber ausnahmsweise auch in Cerebrospinalsystem, d. h. in den dort liegenden trophischen Centren und Bahnen liegen kann.

$\mathrm{Zu}$ den centralen $\mathrm{Z}$ osteren gehören wahrscheinlich jene, welche im Verlaufe gewisser Hirn-Rückenmarkskrankheiten (Tabes, multiple Sclerose, Syringomyelie etc.) vorkommen. $\mathrm{Zu}$ ihnen zählt ferner $\mathrm{Kaposi}$ jene Fälle von recidivirendem und multipel auftretendem Zoster. Er glaubt, dass die grosse Ausdehnung des Processes und das Ueberschreiten der typischen Nervenbezirke eine periphere Erkrankung ausschliesse, und nur erklärt werden könne durch eine Affection des Rückenmarkes, die sich auf den transversalen und longitudinalen Fasern dieses Organes weiter verbreite. Zum gleichen Schlusse gelangte auch Doutrelepont ${ }^{1}$ ) bei einem Falle dieser Art, und in neuester Zeit Hartzell. ${ }^{2}$ )

Diese Veränderungen dertrophischen Centren sind entweder organischer Natur, wie bei den zuerst erwähnten Fällen, oder aber es handelt sich um rein functionelle Störungen, wie sie in erster Linie der Hysterie eigen sind.

1) 1 . c.

2) Recurrent herpes zoster. The americ. Journ. of the med. scienc. XCIX, 4 p. 373. Nr. 216. April. (Ref. in Deut. med. Wochenschr. 1891. Nr. 45.) 
In der Epikrise zu einer Reihe jüngst publicirter Krankengeschichten von atypischen Zosteren sagt K a posi, ${ }^{1}$ ) dass "für die auf so weite Gebiete des Nervensystemes zerstreuten Eruptionen im Gleichen eine zeitweilige Erkrankung oder Labilität der spinalen und vielleicht auch der cerebralen vasomotorischen Centren postulirt werden muss. Solche Störungen sind aber in ähnlicher unberechenbarer Häufigkeit und Mannigfaltigkeit bei Hysterischen zu beobachten." Auffallend ist überdies, dass fast sämmtliche hierhergehörigen Fälle, soweit sie bisher publicirt wurden (Kaposi, ${ }^{9}$ ) Leloir, ${ }^{3}$ ) Neumann, ${ }^{4}$ ) Doutrelepont, $\left.\left.{ }^{5}\right) \mathrm{K} \circ \mathrm{pp}\right),{ }^{6}$ ) Frauen, meist junge Mädchen betreffen, und dass diese zum Theil ausgesprochene Symptome von $\mathrm{Hy}-$ sterie boten: Hemianästhesien, Parästhesien, unregelmässige Menstruation, stumpfes Sensorium oder doch hereditär belastet waren, indem entweder die Eltern oder die Geschwister an nervösen Affectionen litten. Während also einerseits das in seinem Verlaufe wie in seiner Localisation so auffällige Verhalten der Hauteruption auf centrulen Ursprung hinweist, so müssen anderseits die zuletzt genannten Symptome den dringenden Verdacht erwecken, dass die Erkrankung bei diesen Patienten hysterischer Natur ist. - Speciell für unseren Fall möchte ich hervorheben, dass die Kranke, wie wir gesehen haben, ebenfalls an schwerer Hysterie litt, die sich vornekmlich in eigenthümlichen Störungen der Sensibilität, in allgemeinen Convulsionen etc. äusserte. Dann aber sprechen namentich für eine solche Auffassung der Genese der Krankheit deren Beziehungen zur Menstruation, wie sie bereits früher geschildert wurden. Dagegen ist allerdings die Localisation weniger atypisch, als in den anderen analogen Fällen, indem sich das Exanthem die meiste Zeit auf einen bestimmten Nervenplexus beschränkte,

1) Ueber atypischen Z. gangr. u. Z. hyst. Vierteljahrschr. f. Derm. ı. Syph. 1889.

$\left.{ }^{2}\right)$ Wiener med. Wochenschr. $187425,26,38 ; 187522,33 ; 1877$ 25, 28; 18799 und 1. c. (6 Fälle).

3) Recherchez cliniques et anatoms-pathol. sur les affect. cutanées d'origine nerv. Thèse de Paris 1881.

$\left.{ }^{4}\right)$ Anzeiger der k. k. Gesellsch. d. Aerzte in Wien. 1882. Nr. 29.

5) 1. c.

$\left.{ }^{6}\right)$ Münchn. med. Wochenschr. 1886. Nr. 38. 
aber einmal ist doch auch an einem ganz entfernten Orte eine Fruption ausgebrochen und anderseits lehrt uns die Erfahrung zur Genüge, dass nervöse Störungen Jahre lang bestehen und sich dabei auf einen einzigen Nerven oder doch eine Gruppe solcher beschränken können (isolirte Lähmungen einer Extremität, des Nervus recurrens etc.).

Die Prognose des Herpes zoster wird als eine quoad vitam absolut günstige hingestellt. Getrübt kann sie ausnahmsweise werden durch den langwierigen Verlauf der Krankheit, durch zurückbleibende Neuralgien, oder beim J̈erpes zoster des Auges, durch den Verlust dieses Organes. Die im Anfange dieser Arbeit citirten Fälle ändern daran nichts, während allerdings unser eigener Fall auch in dieser Beziehung eine ganz besondere Stellung einnimmt. Mit absoluter Gewissheit können wir ja nicht sagen, was aus unserer Patientin geworden wäre, wenn von Anbeginn der Krankheit an eine exspectative Therapie befolgt worden wäre. Die Erfahrung hat uns gezeigt, dass die Geschwüre in jedem Stadium, auch wenn bereits Infiltration und Gangrän aufgetreten sind, einer spontanen Ausheilung fähig waren. Anderseits ist aber zu bemerken, dass mehrmals die Entzündungserscheinungen aufs Peritoneum, selbst aufs Netz übergegangen waren. Hätte man den Process in diesem Momente nicht aufgehalten, so hätten bei fortschreitendem Zerfalle die schwersten Folgen eintreten müssen; es wäre, wenn die Entzündung zu peritonealen Verklebungen geführt hätte, zur Arrosion von Abdominaleingeweiden oder Netzgefässen gekommen oder wenn die Adhäsionen ausgeblieben oder mangelhaft gewesen wären, zu einer septischen Peritonitis. Jedenfalls darf angenommen werden, dass ohne einen operativen Eingriff der Fall mit grösster Wahrscheinlichkeit lethal verlaufen wäre. Damit soll nun nicht gesagt sein, dass jede Operation ex indicatione vitali vorgenommen wurde; es bezieht sich dies nur auf jene Eingriffe, wo bereits eine Mitbetheiligung des Bauchfelles constatirt wurde, während ich überzeugt bin, dass manche Geschwüre, die gleich zu Beginn der Infiltration entfernt wurden, später auch ohne dies spontan geheilt wären. Trotzdem lässt sich die consequent durchgeführte Excision der Geschwüre rechtfertigen. Denn nachdem es sich einmal herausgestellt hatte, dass die Exstirpation, sofern sie eine gründliche 
war, den localen Process regelmässig coupirte, dass sie die oft unerträglichen Schmerzen beseitigte oder doch linderte, dass sie endlich das Fieber herabsetzte, so war eine sofortige Entfernung der Ulcerationen, sowie sie zu wuchern anfingen, entschieden rationeller als weiteres Zuwarten, denn damit hätte man sich der Eventualität ausgesetzt, später das Bauchfell eröffnen zu müssen. Dies letztere war aber immer ein sehr ernster Eingriff, wenn man bedenkt, dass man eine zum Theil gangränöse, stinkende Masse zu entfernen hatte. Eine Infection des Peritoneums ist in solchen Fällen bei aller Sorgfalt eben nie mit Sicherheit zu vermeiden.

Es ist mehrmals vorgekommen, dass die Operationswunden nicht p. p. heilten, sondern in Folge Durchschneidens der Nähte klafften. Zum Theil rührte dies offenbar von der Spannung der Wunde her; doch bekam man oft den Eindruck, dass es für die Heilung p. p. von Bedeutung war, dass man im Gesunden, und nicht noch innerhalb des zerfallbaren, entzündlich infiltrirten Gewebes operirte (vgl. z. B. Op. 7). Principiell würde sich also die Excision im Gesunden empfehlen.

Neben dieser localen Therapie ist für diese Fälle, gerade weil sie auf Hysterie beruhen, auch eine allgemeine Behandlung nicht ausser Acht zu lassen. Treten allerdings. wie in unserem Falle, die localen Erscheinungen so sehr in den Vordergrund, so wird sich, ausser kräftiger Nahrung und tonisirenden Medicamenten, kaum viel machen lassen. Sind aber die Geschwüre kleiner, verläuft überhaupt der Process in milderer Form, so sollte man auch dem Nervensysteme mit Einschluss. der Psyclee die nothwendige Behandlung angedeihen lassen durch Mastcuren, Hydrotherapie, Wechsel des Klimas und der Umgebung u. s. w. Gerade was das letztere anbetrifft, so ist es doch bemerkenswerth, dass bei unserer Patientin, sobald sie die Anstalt verlassen hatte, die Krankheit rasch sich besserte und schliesslich spontan ausheilte. - Wenn eine solche Allgemeinbehandlung durch die Schwere der Fruption unmöglich. wird, so sollte man wenigstens die Zeit der Remissionen dazu verwenden, um den langwierigen Recidiven nach Kräften entgegenzutreten. 